\title{
O USO DE ESTRUTURAS PASSIVAS EM ESPANHOL POR ALUNOS BRASILEIROS
}

Laís Lagreca de Carvalho ${ }^{1}$

Raquel Fellet Lawall ${ }^{2}$

Resumo: Este trabalho investiga as preferências de uso de estruturas passivas em espanhol (L2) na interlíngua avançada (Selinker, 1972) de falantes nativos de Português Brasileiro (PB) como L1. Para Duarte (1990, apud FANJUL \& GONZALEZ, 2014), ainda que o PB e o espanhol compartilhem todas as possibilidades de construções passivas, eles diferem em suas preferências, pois o PB apresenta maior incidência de uso da passiva perifrástica, enquanto o espanhol prefere a pronominal. Nosso objetivo é verificar o padrão de respostas de um grupo de aprendizes avançados de espanhol (L2) em relação ao uso das passivas através de uma tarefa escrita de completar frases. Buscamos responder se há transferência da L1 para a L2 em estágios avançados de interlíngua, apoiados na Hipótese da Transferência Total e Acesso Total (Schwartz and Sprouse, 1996).

Palavras-chave: Clítico. Interlíngua. Passiva. Transferência.

Introdução

Neste trabalho, buscamos analisar o uso da forma passiva em espanhol por alunos brasileiros, tendo em vista que o espanhol e o Português Brasileiro (PB) compartilham todas as possibilidades de formação de voz passiva, porém, com relação ao uso, as duas línguas apresentam preferências diferentes. Desse modo, pretendemos analisar se a estrutura passiva preferida na L1 dos participantes é transferida para a L2 pelos aprendizes brasileiros de espanhol, caso não haja uma explicitação dessas preferências no aprendizado do espanhol.

Tanto o PB quanto o espanhol dispõem da passiva pronominal com "se" (la passiva refleja) e da passiva perifrástica (analítica, com auxiliar + particípio), como é possível ver nos exemplos abaixo:

(1) Alugaram-se mais casas neste ano do que no ano passado.

Se alquilaran más casas este año que el año pasado.

(2) Depois de toda a confusão, o homem foi detido.

Tras toda la confusión, el hombre fue detenido.

\footnotetext{
${ }^{1}$ Mestranda em Linguística pela Universidade Federal de Juiz de Fora, e-mail: laislagreca@gmail.com.

${ }^{2}$ Doutora em Linguística pela Universidade Federal do Rio de Janeiro, e-mail: raquelflawall@gmail.com.
} 
Com relação às possibilidades de formação de passiva no PB e no espanhol, é possível dizer que há uma simetria entre essas línguas, já que ambas compartilham os mesmos tipos de estrutura, porém, no que diz respeito à preferência de uso há uma assimetria, pois enquanto o PB prefere a passiva perifrástica, o espanhol prefere a passiva pronominal.

Desse modo, tendo em vista as proximidades linguísticas entre essas duas línguas, acreditamos que a não explicitação das preferências com relação à estrutura passiva de cada língua contribui para que ocorra interferência da estrutura preferida pela L1 na produção da L2.

O artigo se divide da seguinte maneira: na seção 1, o fenômeno proposto para análise é discutido assim como a preferência de uso de estruturas passivas entre o PB e o espanhol. Na seção 2, apresenta-se o aporte teórico. Na seção 3, é apresentada tarefa realizada. Na seção 4, expõe-se um caminho para análise dos resultados obtidos. Por fim, tem-se a conclusão do trabalho com apontamentos de possíveis próximos passos.

\section{Preferência de uso da voz passiva em PB e em espanhol}

Este trabalho teve como aporte descritivo o livro organizado por Adrián Pablo Fanjul e Neide Maia Gonzáles, intitulado "Espanhol e português brasileiro - estudos comparados", mais especificamente do capítulo 6, "As formas passivas", escrito por Benivaldo José de Araújo Júnior.

Para tratar das construções passivas escolhidas como recorte: a pronominal e a perifrástica, partimos da definição tradicional de construções passivas. Segundo Araújo Jr., a construção passiva é o oposto da ativa, em que o sujeito desencadeia a ação verbal e recebe, tradicionalmente, o papel semântico de agente, tendo em vista que na passiva o sujeito é afetado pela ação verbal e não o seu desencadeador, recebendo, assim, o papel semântico de paciente.

Com relação à formação de estruturas passivas, Araújo Jr. elenca diversas combinações de formação de passiva no PB e no espanhol, mas afirma que se destacam duas formas nessas línguas: as passivas perifrásticas e as passivas pronominais.

A passiva perifrástica (ou analítica) é formada a partir da combinação do verbo auxiliar ser/ser e do particípio passado do verbo principal, como se pode visualizar nos exemplos abaixo:

(3) O refém foi libertado após o pagamento do resgate. 
(4) El atracador fue detenido por la policía al intentar fugarse.

A passiva pronominal (pasiva refleja) é formada através da combinação de um verbo ativo na 3a pessoa (singular ou plural) e do clítico "se", com função apassivadora, como se pode visualizar nos seguintes exemplos:

(5) Segundo as estatísticas do governo, este ano compraram-se mais geladeiras, fogões e máquinas de lavar que no ano passado.

(6) Se han aprobado leyes que dificultan la inmigración.

A partir da descrição da formação desses dois tipos de passivas, a perifrástica e a pronominal, Araújo Jr. trata das noções de agente e de paciente, questionando a aplicação dos termos "agente" e "paciente", utilizados pela tradição gramatical para classificar as funções semânticas presentes nas construções passivas, e defende que, em muitos casos, essa classificação não corresponde à estrutura argumental do verbo. O autor também analisou construções perifrásticas formadas por auxiliares diferentes do verbo ser, o qual é, muitas vezes, o único apresentado pela definição tradicional.

Ao tratar da incidência de passivas no PB e no espanhol, Araújo Jr., defende que nessas duas línguas, as construções passivas são marcadas, o que contribui para que tanto os falantes do PB quanto os do espanhol prefiram as construções ativas, menos marcadas. Com relação à ocorrência das estruturas passivas nessas línguas, o autor baseia-se no estudo de Duarte (1990) que mostra a preferência para o PB - 63\% de passivas perifrásticas e $37 \%$ de passivas sintéticas (pronominal) - e no estudo de Barrenechea e Rosetti (1979) que mostra a preferência para o espanhol oral portenho - $72 \%$ de passivas sintéticas e $27 \%$ de passivas perifrásticas - para comprovar a preferência dessas duas línguas, que, ainda que compartilhem todas as possibilidades de formação de passiva, têm preferências diferentes. $O$ autor ressalta que os resultados obtidos nos estudos em que se baseia foram tomados de forma absoluta, acrescentando que se as análises tivessem sido feitas por gêneros do discurso, provavelmente, em uns gêneros haveria maior incidência das passivas do que em outros. $O$ autor acredita que a produtividade significativa de construções com clíticos no espanhol contribua para a preferência de construções com "se", diferentemente do que acontece em PB, em que os clíticos não são muito utilizados, pelo menos em uma variedade mais coloquial da língua.

Nesse sentido, acreditamos que a produção de estruturas passivas em espanhol por aprendizes brasileiros de nível avançado pode sofrer transferência da preferência de uso do PB, caso não seja realizada uma explicitação das escolhas de cada língua. 
2. Sobre modelos de transferência no campo de aquisição de segunda língua

Ao pensarmos na possibilidade de transferência de estruturas influenciadas por preferências linguísticas, nos remontamos à década de 90 , em que a pesquisa em aquisição de segunda língua começou a focar na natureza do desenvolvimento das interlínguas (em seu estágio inicial, em seu estágio de desenvolvimento ou na estabilização de todo o processo).

Como os sujeitos que participaram desse estudo são aprendizes avançados de espanhol, espera-se que apresentem uma interlíngua mais estável (Sorace, 2003). No entanto, é preciso investigar se nesse estágio ocorrem ou não transferências da gramática da L1 para a interlíngua do indivíduo.

De acordo com Lawall (2012), a transferência é um fenômeno comum no processo de aquisição de segunda língua e, de acordo com Odlin (1989), a transferência é resultado das semelhanças e das diferenças encontradas entre a língua alvo e a outra língua. Assim, é possível pensarmos que a L1 exerce influência sobre a interlíngua de um aprendiz de L2.

Há teorias como a Teoria de Transferência e Acesso Total (Full Transfer/Full Access Hypothesis, Schwartz \& Sprouse, 1994,1996) que afirmam que a gramática completa da L1 é o estado inicial da gramática da L2 (Lawall, 2012), de modo que nos faz pensar que não há como esperar que em se tratando de aprendizado de uma L2 não haja algum tipo de interferência da gramática, já consolidada, da L1. Desse modo, em uma situação de aquisição de L2, quando a gramática da L1 não é capaz de acomodar o input da L2, no desenvolvimento da interlíngua, essa acaba sendo reestruturada de acordo com os princípios da GU, por isso, entende-se como "acesso total". A interlíngua apresenta um estágio estável que é sempre diferente do da L2, na medida em que algumas propriedades da gramática da L1 do falante vão sempre o afetar e fazer com que sejam notadas propriedades da L2. Essa colocação da interlíngua em um nível que recebe influência da L1 e percebe como distinta a L2, pode levar a fossilizações em alguns domínios linguísticos e a uma interlíngua sempre distinta da língua alvo.

Com base, então, na Teoria de Transferência e Acesso Total, é possível pensarmos que regras da L1, no caso específico deste trabalho, o PB, dos aprendizes de espanhol como L2, mesmo em um estágio avançado de interlíngua, podem interferir na construção de determinadas estruturas na L2, como no caso das estruturas passivas. Acreditamos que a simetria existente com relação às estruturas passivas nessas línguas somada a uma não explicitação da assimetria da preferência de uso em cada uma das línguas, possa potencializar a interferência da preferência de uso da estrutura da L1 na produção da L2. 
3. Teste piloto - Construção de frases com estruturas passivas

Nesta seção, apresentamos um teste piloto de produção escrita de completar sentenças. $O$ objetivo desse teste era verificar a possível transferência da estrutura passiva da L1 na produção da L2. Para a realização dessa tarefa, os participantes tiveram que completar sentenças, unindo partes previamente oferecidas, conjugando o verbo no Pretérito Indefinido, de modo que a sentença fizesse sentido. Para facilitar a compreensão do que o teste propôs, seguem abaixo exemplos de sentenças:

Construye frases en pretérito indefinido con las partes que siguen.

'Construa frases no pretérito indefinido com as partes oferecidas'

Ejemplos:

'Exemplos'

Los ladrones / acercarse / a mí muy rápidamente

'Os ladrões / aproximar-se / de mim muito rapidamente'

Los ladrones se acercaron a mí muy rápidamente

'Os ladrões aproximaram-se de mim muito rapidamente'

Rosa y Pablo / estar / en la fiesta sábado

'Rosa e Pablo / estar / na festa sábado'

Rosa y Pablo estuvieron en la fiesta sábado

'Rosa e Pablo estiveram na festa sábado'

A solicitação de que o verbo fosse conjugado no Pretérito Indefinido tinha como propósito que em sentenças como as seguintes, fosse usada a voz passiva:

La tienda / saquear/ el mes pasado

'A loja / roubar / no mês passado'

Se saqueó la tienda el mes pasado / La tienda fue saqueada el mes pasado 'Roubou-se a loja no mês pasado / A loja foi roubada no mês passado' 
El caso / investigar / a fondo

'O caso / investigar / a fundo'

Se investigó el caso a fondo / El caso fue investigado a fondo

'Investigou-se o caso a fundo / O caso foi investigado a fundo'

Esas materias / no enseñar / adecuadamente

'Essas matérias / não ensinar / adequadamente'

No se enseñaron adecuadamente esas materias / Esas materias no fueron enseñadas adecuadamente

‘Não ensinaram-se adequadamente essas matérias / Essas matérias não foram ensinadas adequadamente'

\subsection{Método}

\subsubsection{Participantes}

Participaram desse experimento 12 falantes nativos do PB, aprendizes avançados de espanhol (alguns poucos já eram graduados) e participaram 12 falantes nativos de espanhol, de várias nacionalidades, os quais formaram o Grupo Controle. Esse grupo foi importante para a confirmação da estrutura preferida pelos falantes nativos de espanhol.

Cada participante completou 36 sentenças, sendo 12 sentenças experimentais e 24 sentenças distratoras (Anexo 1). Essas sentenças foram analisadas qualitativa e quantitativamente.

\section{Análise de dados}

Como professores de línguas estrangeiras, é preciso sempre levar em consideração as possíveis transferências feitas pelos aprendizes da L1 para a L2. No caso específico do PB e do espanhol, essa transferência pode ser ainda mais recorrente, tendo em vista a proximidade entre essas duas línguas, por essa razão, é muito importante que o docente seja sensível a esse processo e perceba em quais momentos uma sistematização mais explícita de determinados elementos deve ocorrer. 
Ao aplicarmos a tarefa, tanto no Grupo Controle como no Grupo Teste tivemos 4 tipos de respostas: (i) passiva pronominal; (ii) passiva perifrástica; (iii) simples concordância verbal e (iv) indeterminação do sujeito. Como podemos visualizar a seguir:

La tienda / saquear/ el mes pasado

'A loja / roubar / no mês passado'

(i) Se saqueó la tienda el mes pasado.

'Roubou-se a loja no mês passado'

(ii) La tienda fue saqueada el mes pasado.

'A loja foi roubada no mês passado'

(iii) La tienda saqueó el mes pasado.

'A loja roubou no mês passado'

(iv) Saquearon la tienda el mes pasado.

'Roubaram a loja no mês passado'

Podemos comparar as escolhas feitas entre o Grupo Controle e o Grupo Teste, a partir do seguinte gráfico:

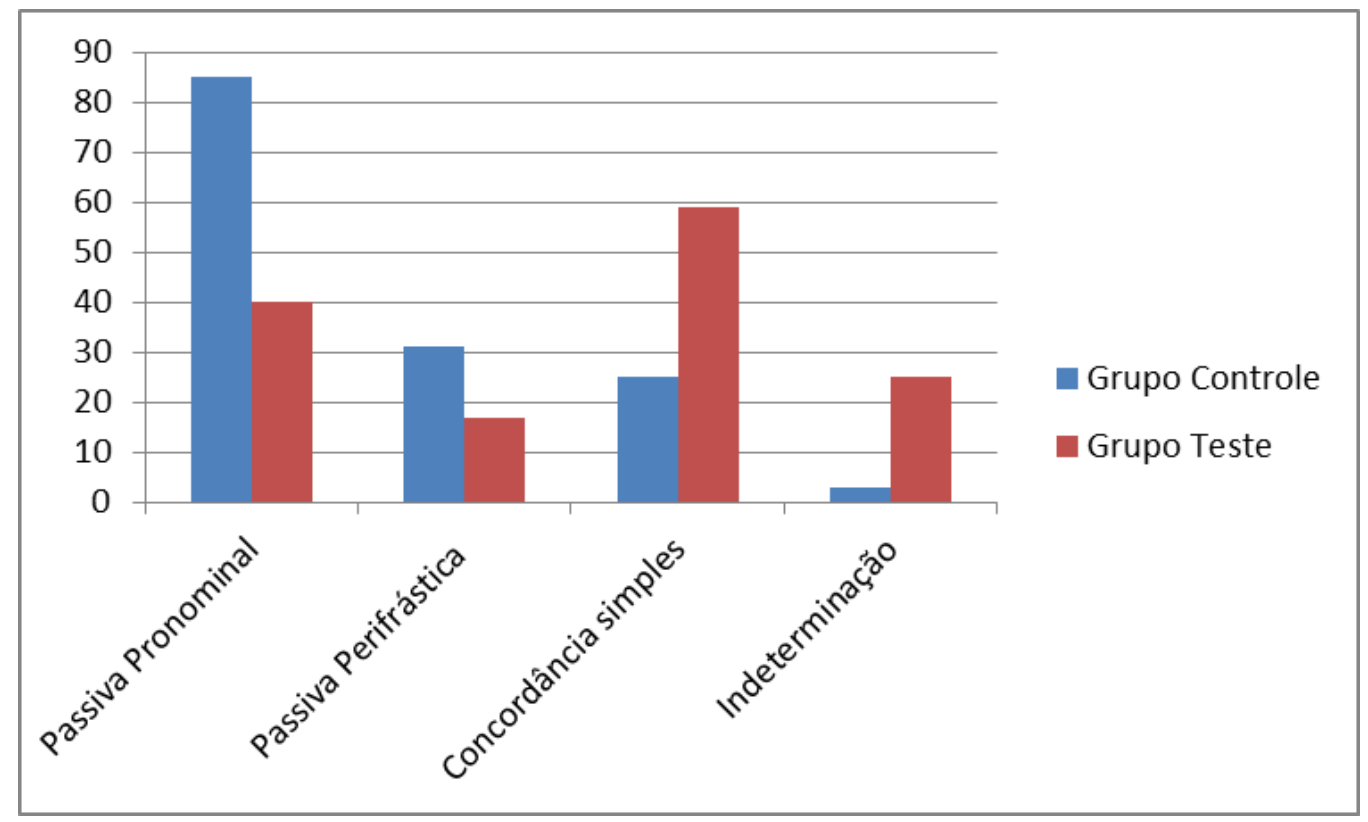

Com base nesse resultado, pudemos confirmar a preferência dos falantes de espanhol como L1, pela voz passiva pronominal, como apontado por Barrenechea e Rosetti (1979) para o espanhol portenho, que teve predominância entre suas respostas (85 de 144 vs. 40 de 144 no Grupo Teste). No entanto, ao olharmos para as respostas dos falantes de espanhol como L2, percebemos que a maior ocorrência foi de sentenças com o verbo com uma simples 
concordância com um "possível" sujeito (59 de 144), o elemento que deveria ocupar a posição de complemento do verbo e ser afetado pela ação verbal. A voz passiva perifrástica teve 17 ocorrências no Grupo Teste e 40 no Grupo Controle. Ainda houve a reposta de indeterminação do sujeito que no Grupo Teste foi de número 25 e de número 3 no Grupo Controle.

Com base nas respostas dos participantes e de acordo com uma análise quantitativa e qualitativa, podemos levantar algumas questões como o uso de clíticos no PB e pensar se a pouca incidência de clíticos nos dialetos de Minas Gerais, como apontado em estudos como o de D'Albuquerque $(1982,1984)$ e o de Ribeiro (2010), pode ter influenciado na produção dos sujeitos; podemos pensar, também, se os participantes que não produziram sentenças na voz passiva estão tendo dificuldades em reconhecer e/ou produzir essa estrutura na tarefa, tendo em vista que se trata de uma construção marcada em ambas as línguas. Sendo este um teste piloto, faz-se necessário coletar mais dados e pensar talvez outra metodologia experimental para compreendermos, de forma mais clara, o padrão de comportamento dos falantes de PB em relação às preferências de uso da voz passiva em espanhol como L2.

\section{Considerações Finais}

O experimento apresentado neste trabalho partiu da hipótese de que os alunos brasileiros avançados de Espanhol como L2 transfeririam a preferência da forma de passiva mais utilizada no PB, a perifrástica, para o espanhol, através de uma tarefa de completar frases.

Com base na aplicação desse teste piloto, pudemos confirmar a preferência da construção passiva nos falantes de espanhol, a passiva pronominal. Com relação aos falantes de PB como L1, os dados indicam que parece haver uma dificuldade de compreensão de estruturas passivas, a qual pode ser resultado de uma não explicitação desse tema na formação desses sujeitos. Além disso, é preciso considerarmos o contexto em que a tarefa foi aplicada, tendo em vista que os falantes de PB como L1 eram majoritariamente mineiros, da cidade de Juiz de Fora, onde vem se perdendo o uso de clíticos na fala, já que é comum que escutemos algo como "não preocupa, não" "ii eu arrependi de não ter ido...".

Desse modo, acreditamos que esse teste piloto pode servir como base para a continuidade deste trabalho, pois através dele foi possível demonstrar o pouco reconhecimento de estruturas passivas por partes de estudantes avançados de espanhol como L2. Com isso, reforçamos a importância de haver no ensino de espanhol como L2 momentos em que a Língua Portuguesa seja utilizada como estratégia para elucidar as semelhanças e as diferenças de preferências entre essas duas línguas. 


\title{
The Use of Passive Structures in Spanish by Brazilian Students
}

\begin{abstract}
This paper investigates the preferences in the use of passive structures in Spanish (L2) in advanced interlanguage (Selinker, 1972) of native speakers of Brazilian Portuguese (PB) as L1. For Duarte (1990, apud FANJUL \& GONZALES, 2014), although PB and Spanish share all the possibilities of passives constructions, they differ in their preferences, since PB presents a greater incidence of use of the periphrastic passive whereas Spanish prefers the pronominal. Our objective is to verify the pattern of responses of a group of advanced learners of Spanish (L2) regarding the use of the passive through a written task of completing sentences. We seek to answer if there is transfer from L1 to $L 2$ in advanced stages of interlanguage, supported by the Full Transfer Full Access Hypothesis (Schwartz and Sprouse, 1996).
\end{abstract}

Key words: Clitic. Interlanguage. Passive. Transfer.

Referências

D'ALBUQUERQUE, Alair. R. A perda dos clíticos num dialeto mineiro. Tese de Doutorado, UFRJ, 1982.

D'ALBUQUERQUE, Alair. R. A perda dos clíticos num dialeto mineiro. Tempo Brasileiro, 78/79, 97-121, 1984.

FANJUL, Adrian Pablo (Org.) ; GONZALEZ, N. T. M. (Org.) . Espanhol e português brasileiro: estudos comparados. 1. ed. São Paulo: Parábola Editorial, 2014. v. 1.

FERRARI et alii. A interpretação passiva/indeterminada de construções com a partícula se em tempos simples do português brasileiro - um estudo em sintaxe experimental. DLCV, João Pessoa, v.7, n.1, jan/jun 2010, p.39-56.

LAWALL, Raquel Fellet. A alternância causativa/incoativa em espanhol como L1 e L2. ReVEL, v. 10, n. 18, 2012. [www.revel.inf.br]. 
RIBEIRO, Pablo. A alternância causativa no Português do Brasil: A distribuição do clítico se. Dissertação de Mestrado, UFRGS, 2010.

SELINKER, Larry. Interlanguage. IRAL, 10, (3), 209-231, 1972.

SCHWARTZ, Bonnie; SPROUSE, Rex. L2 cognitive states and the full transfer/full accessmodel. Second Language Research 12:40-72, 1996.

\section{Anexo I}

Construye frases en pretérito indefinido con las partes que siguen.

Ejemplos:

Los ladrones / acercarse / a mí muy rápidamente

Los ladrones se acercaron a mí muy rápidamente

Rosa y Pablo / estar / en la fiesta sábado

Rosa y Pablo estuvieron en la fiesta sábado

La abuela de Lucía / teñir / el pelo en su casa

Mi hermana / prestar / a mí el vestido para la fiesta

La tienda / saquear/ el mes pasado

La pareja / abrazarse / muy fuerte

El caso / investigar / a fondo

María / encontrar / las carpetas en las que estaban los documentos

El candidato a la presidencia / perder / nuestros votos ahora mismo

Los músicos / empezar / la presentación dedicada a la princesa 
El móvil / romperse / muy rápidamente

Aquella amiga tuya que / conocer / en la fiesta

La autora / dedicar / este capítulo a usted

Esas materias / no enseñar / adecuadamente

La madre / encontrar / a los niños perdidos

Escenas violentas / mostrar / en la TV

Los niños no / decir / la verdad a sus padres

Los amigos / conocerse / en una fiesta de cumpleaños

El estadio de la Copa / inaugurar / el año pasado

La médica del hospital / llegar / muy retrasada

Los chicos no / hacer / sus tareas de casa

La novela "Vidas Secas" / traducir a varios idiomas

A los perros les / gustar / los nuevos juguetes

El chico / enfermarse / para faltar a la clase

Muchas huellas de los delincuentes / encontrar / allí

Juan / lastimarse / a causa del resultado de la prueba 


\begin{tabular}{|l|}
\hline La profesora de la escuela / homenajear / la semana pasada \\
\hline La película / permanecer / en cartel por un año \\
\hline Los políticos no / querer / luchar por el bien de la nación \\
\hline \\
\hline El proyecto social / extinguir / en el último año \\
\hline Marina / romperse / el brazo en las vacaciones pasadas \\
\hline La abogada / escuchar / todo el juzgamiento con mucha atención \\
\hline Las costumbres / crear / en los pueblos antiguos \\
\hline Las grandes ciudades no / soportar / más tanta polución \\
\hline
\end{tabular}

